Published as: Greenhill, R. \& Griffiths, M.D. (2014). The use of online asynchronous interviews in the study of paraphilias. SAGE Research Methods Cases. Located at: http://dx.doi.org/10.4135/978144627305013508526

Methods in Action

The use of online asynchronous interviews in the study of paraphilias

Richard Greenhill and Mark D. Griffiths

Psychology Division

Nottingham Trent University

Nottingham

NG1 4BU

mark.griffiths@ntu.ac.uk 


\section{Contributor biographies}

Richard Greenhill is a postgraduate student of psychology at the Nottingham Trent University. His research interests include sexual paraphilias and online research methods in sexuality.

Dr. Mark Griffiths is a Chartered Psychologist and Professor of Gambling Studies at the Nottingham Trent University, and Director of the International Gaming Research Unit. He has spent over 25 years in the field is internationally known for his work into gaming and gambling. He has published over 430 refereed research papers, three books, $100+$ book chapters, and over 1000 other articles. He has served on numerous national and international committees and gambling charities (e.g., National Chair of GamCare, Society for the Study of Gambling, Gamblers Anonymous General Services Board, National Council on Gambling etc.). He has won 14 national and international awards for his work including the John Rosecrance Prize (1994), CELEJ Prize (1998), Joseph Lister Prize (2004) and the US National Council on Problem Gambling Research Award (2009). He also does a lot of freelance journalism and has appeared on over 2500 radio and television programmes. Dr Griffiths is an active blogger including his personal blog (http://drmarkgriffiths.wordpress.com) and one for Psychology Today (http://www.psychologytoday.com/experts/dr-mark-d-griffiths-phd). 


\section{Relevant disciplines}

Psychology

\section{Academic level}

Intermediate undergraduate; Advanced undergraduate; Postgraduate

\section{Methods used}

Qualitative research design; Qualitative data collection; Online data collection; Online interviews

\section{Keywords}

Online asynchronous interviews; Paraphilias; Sexual behaviour; Online methodologies;

Online data collection

\section{Link to the research project}




\section{Learning outcomes}

- This case provides an overview of the use of online asynchronous interviews to collect data from rare sexual paraphilias and seeks to give new researchers a better understanding of the methodological issues faced when using online asynchronous interviews in carrying out research into sexual paraphilias.

- To understand the advantages and disadvantages of using online asynchronous interviews as a means of accessing sensitive populations within sexuality.

- To understand the way in which the nature of the Internet impacts the use of online data collection methods.

- To be able to critical evaluate the use of online asynchronous interviews in relation to other online data collection methods.

\section{Introduction}

Sexual paraphilias (and sexual fetishes) are represented in the psychological literature primarily as pathological conditions that need to be treated by a clinician. However, very little research exists into 'healthy' paraphilias that an individual enjoys as part of a healthy sexual lifestyle and without any clinical problems. This has been attributed in part to both researcher and participant. On the one hand, many researchers may be reluctant to research non-normative areas in sexuality out of fear that their personal interests may be aligned with the non-normative interests in question (Okami, 2002). On the other hand, paraphilias and sexuality in general may represent a taboo, sensitive and private aspect of an individual's life, meaning that they are unwilling to disclose information about it face-to-face and/or in public. The Internet represents an online space in which individuals can quickly and easily disclose information while maintaining perceived anonymity. As such, the Internet offers the perfect opportunity for carrying out research into 'healthy' paraphilias (Griffiths, 2012a). There are 
currently numerous methodologies that can be used to collect online data about sexual paraphilias. However, this case study briefly examines a common online qualitative method (i.e., online asynchronous interviews) and briefly reviews its advantages, disadvantages and uses.

\section{The use of online methodologies to study sexual paraphilias}

Online methods are becoming increasingly popular in the study of paraphilic behaviours, owing to the numerous advantages they hold over traditional offline research methods. The Internet is a versatile research tool and can be used to conduct correlational, cross-sectional, experimental, self-report and/or observational research within the discipline of psychology. Griffiths (2012a) recently examined four different online data collection methods used for collecting paraphilic data, including: (i) online questionnaires; (ii) online forums; (iii) online interviews; and (iv) online participant observation. He concluded in this review that online data collection methods represent a useful and practical way in which to research sexual paraphilias.

Online methodologies hold a number of advantages over traditional offline methodologies when it comes to studying paraphilic behaviour. Griffiths (2012a) argues that the Internet is advantageous because it: (i) provides the opportunity for anonymous behavioural research with previously inaccessible populations (i.e., paraphiliacs) and especially those with rare paraphilic interests; (ii) can be useful for eliciting rich and detailed data in sensitive/unusual/embarrassing areas (i.e., paraphilic behaviour); (iii) has a disinhibiting effect on participants and reduce social desirability bias, leading to increased levels of honesty and therefore higher validity in the case of self-report; (iv) provides access to participants who may not have taken part in offline research (i.e., paraphiliacs); (v) provides 
access to a potentially global pool of participants, thereby increasing the possibility to study extreme and uncommon behaviours (i.e., paraphilias) and allowing for quick and easy crosscultural comparisons to be made; (vi) provides access to 'socially unskilled' participants (i.e., some paraphiliacs), who may not have taken part in offline research; (vii) can aid participant recruitment through advertising on different bulletin boards and websites (e.g., paraphilia chat rooms, paraphilia forums); (viii) can contain archived material for use in time-based qualitative research; and (ix) produces data that can be automatically transcribed, suiting particular methodologies (e.g., interpretative phenomenological analysis, discourse analysis, etc.). In additional to these nine advantages, it is also commonly argued that the Internet reduces financial and time costs, owing to the lack of preparation and dissemination costs and quicker participant response times online (Granello \& Wheaton, 2004).

\section{Asychronous or synchronous interviews?}

Internet technology allows for two types of online interview: the asynchronous and synchronous interview. An asynchronous interview is one in which data are transmitted intermittently (i.e., via an e-mail client, such as Hotmail or Gmail), while a synchronous interview is one in which data are transmitted in a steady stream (i.e., via an Instant Messaging (IM)/chat client, such as MSN Messenger or ICQ). Both types of online interview fulfill all of the advantages of online methods set out above and are therefore appropriate for use in studying paraphilic behaviours. In addition to these advantages, both types of online interview have the added caveat that interviewees can take their time to create thoughtful and reflective responses that can be edited at some point if need be. Likewise, both types of online interview carry the disadvantage that nonverbal (e.g., body language) and paralinguistic (e.g., tone of voice) cues are not available. This makes it difficult for the researcher to know the psychological disposition of participating interviewees and limits the 
possibilities within analytic techniques that often rely on these cues (e.g. conversation analysis). Furthermore, there are a number of advantages and disadvantages to both types that should be considered before a researcher chooses either type of online interview.

Asynchronous interviews - Advantages and disadvantages:

Asynchronous interviews have a number of advantages (James \& Busher, 2006): (i) responses can be sent at the participant/researcher's own convenience, making the interview process less stressful for both parties; (ii) complications caused by time zone differences and technical difficulties are avoided, as the interview can be resumed at an appropriate time or once technical difficulties have subsided; (iii) e-mail technology is quick and easy to use, as most people who use the Internet already have an e-mail account; and (iv) interviewees can take more time to reflect and write their responses without the implied presence of the researcher.

However, asynchronous interviews also have a number of disadvantages (James \& Busher, 2006): (i) responses can be incoherent owing to the gap between asking a question and following-up; (ii) it is difficult to immediately clarify the meaning of an ambiguous or misunderstood question; (iii) questions may come across in the wrong way and lead to interviewees withdrawing; (iv) interviewees are unaware of how many questions will be asked in total, which may cause stress; and (v) e-mails may be sent to a junk folder or remain unseen by interviewees, effectively ending the interview.

Synchronous interviews - Advantages and disadvantages:

Synchronous interviews have a number of advantages (Jowett et al., 2011): (i) both parties can engage in real-time conversation, leading to more coherent responses; (ii) there is a 
quicker response time than in asynchronous interviews; (iii) interviewees are more likely to display speech disfluency (e.g., fillers), which can be useful when employing certain analytic techniques (e.g., conversation analysis); (iv) any ambiguities in the study or questions can be immediately addressed by the researcher.

However, synchronous interviews also have a number of disadvantages (Jowett et al., 2011): (i) time zone differences and technical difficulties may interrupt the study or make it difficult to carry out; (ii) interviewees are required to have a certain level of prerequisite knowledge (i.e., may never have used an IM client before); (iii) interviewees can become distracted by other activities on their computer, leading to lengthy interviews (e.g., around three hours); (iv) pauses may be misinterpreted by interviewees as researcher disinterest.

\section{Considerations in choosing type of online interview}

Owing to the number of individual advantages and disadvantages to asynchronous and synchronous interviews, there are a number of considerations to bear in mind before choosing to use either type of interview. These considerations can be summarised as follows:

1. Geographical location of participants. Researchers should consider where their participants are based. If their time zone is significantly out of sync with that of the researcher, then it is probably best to choose asynchronous interviews. On the other hand, if they are based in the same country as (or a country adjacent to) the researcher, synchronous interviews may be advantageous.

2. Demographics of participants. Certain demographic features of the participants should be considered (e.g., age, nationality, education, etc.). If the researcher is specifically targeting elderly participants, they may be comfortable with using e-mail, 
but not an IM client. Likewise, those participants possessing a higher education are more likely to have used computer technology throughout their education (Ross et al., 2005) and as such may find it easier to use an IM client.

3. Timeframe of the study. Study schedules should be considered and researchers should evaluate how much time they have to collect data. Asynchronous interview questions can go unanswered for weeks and may require frequent following-up. On the other hand, synchronous interviews can be carried out within a single session across a few hours.

4. Analytic technique. Researchers need to consider which technique they will use to analyse the data. Generally speaking, online interviews do not lend themselves well to discourse analysis. However, as pointed out above, synchronous interviews may work to some extent with conversation analysis.

The next section briefly puts these considerations into practical application by using asynchronous interviews to collect data from a little researched sexual paraphilia (i.e., dacryphilia - sexual arousal from crying and/or tears)

\section{Case study method in action: Establishing a dacryphilia typology}

This section examines a research project into dacryphilia, one of many under-researched paraphilias. What follows is a contextual overview of the research, as well as a look at the research design, methodological strengths and limitations and some critical reflections on the whole methodological process. Although the project focused specifically on dacryphilia, the guidance in this section can be applied to studies into any other paraphilias.

Research context and overview: 
The majority of psychological literature on paraphilias treats them as pathological disorders that need to be treated clinically. However, numerous studies (e.g., Scorolli et al., 2007; Ahlers et al., 2011) have shown that 'healthy' paraphilic interests (i.e., paraphilias enjoyed as part of a healthy sexual lifestyle and without causing distress to the paraphiliac or their partner) are widespread and constitute a part of many individuals' sex lives. In spite of this, there is a dearth of empirical research that looks into the experiences of different paraphiliacs and examines the phenomenology of their paraphilic interests. This was the initial gap in the literature that the research in this case study sought to address.

Estimates place the number of recognised paraphilias as somewhere between 547 and $750+$ (Love, 2002; Aggrawal, 2009). These paraphilias can range from the relatively well known (e.g., zoophilia, a sexual attraction to and interest in animals) to the largely unheard of (e.g., homilophilia, sexual arousal from listening to/giving sermons or speeches). As such, the next step was to choose a paraphilia that was under-represented in the psychological literature and had good research potential. Dacryphilia has been defined as "arousal from seeing tears in the eyes of a partner" (Aggrawal, 2009, p. 373), with a further widened definition including “(i) sexual arousal from someone displaying strong emotion and/or (ii) sexual arousal from the emotional release that accompanies crying (i.e., an "emotional catharsis")." (Griffiths, 2012b). This was chosen as a suitable paraphilia because it opens a number of potential research possibilities (i.e., sadistic, masochistic, emotional, active and passive interests within dacryphilia) and also appears to be an extension of normative human behaviour (i.e., the impulse to give attention to and comfort a crier).

Since this was the first study of its kind into dacryphilia, it was decided that a set of qualitative interviews represented the best methodological approach. These would help to 
achieve the research aims of establishing a typology of different interests within dacryphilia and exploring the range of dacryphilic experience. Ultimately, the study found a number of different types of dacryphilic interest (e.g., compassionate dacryphilia and Dominant/submissive dacryphilia) and established specific features that characterise these types. These findings were discussed both in relation to the wider paraphilia literature and psychological literature on crying and tears.

\section{Research design:}

Given the research aims and as mentioned above, it was decided that qualitative interviews represented the best methodological approach to the study. Likewise, dacryphilia (like most paraphilias) is a sensitive and 'niche' interest that most dacryphiles discuss online, rather than in public. As such, online interviews were chosen as the most appropriate way to get in touch with a big enough sample to explore this paraphilic behaviour further. The final decision was whether the online interviews should be asynchronous or synchronous. On beginning the research, it soon became apparent that the majority of dacryphiles encountered on online forums were from the United States. Similarly, the only inclusion criterion was identification as a dacryphile, meaning that no specific demographic group was targeted. Finally, recruitment commenced a number of months before the project deadline and the preferred analytic technique was thematic analysis. This meant that asynchronous interviews arguably represented the best way in which to interview the participants.

All participants were initially sent the same set of structured preliminary questions, designed to obtain: (i) demographic information (e.g., age, nationality, education); and (ii) a basic profile of the participant's dacryphilia (e.g., first dacryphilic experience, specific types of arousal within dacryphilia, other sexual interests, etc.). Examples of the latter included: 
- What was your first experience of dacryphilia like?

- How open are you with others about your interest in dacryphilia?

- Do you get any sexual pleasure if other people watch you cry?

- Do you think there is any connection between your fetish and other fetishistic behaviour that you engage in?

- Would you describe your dacryphilia as sadistic and/or masochistic?

These were then followed by a set of unstructured participant-led questions (i.e., the unstructured questions were grounded in the participants' responses to the structured questions) about the participants' dacryphilia. Depending on how interviewees answered the initial set of questions (i.e., what their specific responses were, the depth of their responses, etc.), the subsequent set ranged from eight to nineteen questions. Examples of these included:

- You mention that your caring/compassionate nature feeds into your quirk. Can you elaborate on this?

- You mention that you have scored highly on (informal) tests for sociopathy. Do you recognise sociopathic traits in yourself? If so, to what extent do you feel that these have an influence on your sexuality?

- You imply that it is difficult to find men who can engage in dacryphilia in a way which fully satisfies you. Why do you think that "often men don't have it in them to truly hurt me"?

- Can you give an example of a hurt/comfort scenario that you did with your stuffed animals when you were young? 
- Do you feel that your upbringing as an only child may be connected to your involvement with dacryphilia?

Following the second set of follow-up questions, no more questions were sent to the participants. However contact was maintained so that feedback could be gained from participants on the names and definitions of the different dacryphilic types.

\section{Strengths and limitations:}

The data produced by asynchronous interviews in the study were sufficient enough to highlight two distinct types within dacryphilia and allow a detailed analysis of these two types. In particular, the methodological approach displayed the following strengths:

- An adequate sample size $(n=8)$ for qualitative research was recruited from a range of countries (USA, Belgium, Romania, UK), the majority of which were outside of the home institution country. If recruitment had been carried out offline, it is unlikely that any participants, such as the ones recruited here, would have come forward.

- All participants were recruited from online forums, which increased the likelihood that they were competent in using computers and the Internet.

- Participants were free to respond to questions at their own convenience, which avoided any problems caused by time-zone differences or prior work/social arrangements. 
- The majority of participants gave rich descriptive and reflective accounts of their experiences of dacryphilia. This allowed for an in-depth qualitative analysis of the data and may not have been achieved through synchronous interviews.

- Informed consent forms were sent via e-mail and with the initial set of questions that ensured continuity between the informed consent process and the start of the interview.

- Participant feedback was maintained via e-mail throughout the whole research process, which meant that rapport was built between the participants and researcher and that the results were a fair reflection of the participants' dacryphilic experience.

Despite these many strengths, there were also a number of limitations to the study. Some of these limitations arose as a result of using online methods (e.g., absence of nonverbal and paralinguistic cues) and as such will not be discussed here because they were already implied in the initial choice of online methods. The methodological approach directly entailed the following limitations:

- During recruitment on one online forum, concerns were expressed by the forum members about the legitimacy of the research project and the researchers' identities. These concerns were resolved when one of the members contacted the senior researcher in the research team. Employing another online method (e.g., asynchronous video interview) may have addressed at least some of the concerns regarding the researchers' identities. 
- One potential participant expressed an interest in taking part in the study, but after reviewing the messages she had sent the researcher, the researcher decided that her participation may have posed an ethical risk (i.e., it may have caused her emotional and/or psychological distress). Asynchronous online interviews make it more difficult to offer helpful and practical support, because a participant can simply decide to stop replying to e-mails.

- One potential participant expressed an interest in taking part in the study and filled out both the informed consent form and the initial set of questions. However, he did not possess the required technical knowledge to e-mail the completed documents back and therefore did not provide any data to be included in the study.

- Some questions implied 'yes' or 'no' responses (e.g., "Do you get any sexual pleasure if other people watch you cry?"). The researcher had hoped that participants would elaborate on these responses (e.g., "Yes, I get sexual pleasure if...but not when..."). However, this typically did not happen and needed to be followed-up in the subsequent set of questions.

- If participants were unclear on the meaning of a question, it usually took (the researcher that collected the data) one or two days to reply to their query. This may have had a detrimental effect on the coherency and/or the veracity of their written responses.

- One participant gave limited responses, usually consisting of one small sentence per question. Owing to the lack of real-time interaction, it was impossible for the researcher to prompt him to give more detailed responses. This meant that his data could not be used to the same extent or depth as other participants' responses. 


\section{Critical reflections}

The data gained from using online asynchronous interviews was subsequently analysed using thematic analysis. This gave rise to a set of two distinct dacryphilic types, characterised by a number of sub-themes. Without the use of asynchronous interviews, this would not have been possible, as it is likely that very few (if any) participants would have been recruited and that there would have been potential time-zone difficulties with those that were recruited. Likewise, despite the long data collection period (i.e., 6 months), the nature of asynchronous interviews meant that time was saved during the traditional transcription and data cleaning period (i.e., the data was already transcribed and the responses were to the point, rather than containing the conversational chit-chat of face-to-face and synchronous interviews). Finally, it was always possible to maintain contact with participants via e-mail, leading to increased rapport with participants that was reflected in their appreciative replies to the researchers. As such, the choice of asynchronous interviews in the methodological approach to this study can be considered a success in terms of collecting useful and usable data.

However, there were also a number of limitations in the use of asynchronous interviews. Although rapport was built with participants following recruitment (as well as during and after the interview process), participants on one of the online paraphilia forums expressed concerns about the legitimacy of the researcher collecting the data and the research project itself. Clearly, this problem is avoided in traditional face-to-face research, but this is not particularly an option in the study of paraphilias. The use of synchronous interviews or another online method (e.g., online questionnaires) may have allayed this problem somewhat, as IM clients and online questionnaires may appear more 'technological' and befitting of proper academic research than the relatively traditional and simple e-mail client. Likewise, if synchronous interviews had been utilised participants would have been able to actively question the researchers in real-time, which may have appealed as a means of assessing 
legitimacy. Willis (2011) suggests that by becoming familiar with the research population's online parlance (e.g., the use of abbreviations such as LOL, OMG, etc.) and mimicking this linguistic style, online trust can be built and maintained. However, given the problem that the research team's identities were cast into doubt, the use of online parlance may have only served to further delegitimise the study. Ultimately, this problem was resolved when a member contacted the most senior member of the research team. As such, this problem may occur more frequently to those who are new to research and/or with limited prior publications, especially when carrying out asynchronous interviews. In this case, the best solution may lie in referring individuals to a more established member of the research team (who is likely to have an established profile that can be checked online by potential participants), or attempting to establish legitimacy through referring individuals to the research team's own university profile or publications from research team members.

Elsewhere, there were issues with gaining detailed responses of a depth that allowed rigorous qualitative analysis, both in general (i.e., with implied 'yes' or 'no' responses) and specifically with one participant. Clearly, this problem is likely to be avoided and/or overcome in synchronous interviews. If asynchronous interviews are to be used, this limitation can be managed more effectively by designing open-ended questions that do not solely imply 'yes' or 'no' responses. For example, rather than simply asking "Do you get any sexual pleasure if other people watch you cry?", an additional question can be added, such as "If so (or not), can you elaborate on why this happens/does not happen?". This sort of question can be asked in the follow-up questions. However, by adding it to the initial questions, time is saved and veracity and/or coherency is likely to be improved. In the case of limited individual responses, participant data may have to be discarded if it is entirely unusable. Alternatively, follow-up questions for the participants could be tailored so that 
fewer questions are sent over a much longer time period (i.e., rather than ten questions in one e-mail, five e-mails could be sent each including two questions). This may appear less daunting and encourage participants to focus more attention on each individual question.

Finally, the research outlined in this case study was limited by participant issues that occasionally concerned ethics, technology and question ambiguity. Within asynchronous interviews, these issues can be difficult to avoid, as all participants are different and there is always a chance that one of them may have experienced distress in the past, may not understand how to use e-mail technology and/or may not understand the exact intent of a question. The best way to avoid such limitations is by giving clear instructions with the initial questions about how to respond to questions, how to submit responses through e-mail and what to do in the case that ethical issues are raised (e.g., leave details of a support group such as Samaritans). Similarly, by checking e-mails at least once a day, the researcher can ensure that any questions regarding the aforementioned issues are addressed as soon as possible and do not impact the study's participants too greatly.

\section{Conclusions}

This case study has highlighted that online asynchronous interviews represent a useful and advantageous research tool in the study of sexual paraphilias, by discussing their use in a specific research project carried out by the present authors on dacryphilia. However, it was also shown that asynchronous interviews can display a number of disadvantages when compared to other online methods (i.e., synchronous interviews). The primary decision for researchers studying paraphilias is whether their choice of online interview is suitable and realistic for their research population and proposed research design. In the study here, the advantages of asynchronous interviews far outweighed the disadvantages, when considering 
the location and demographics of the research participants, the proposed analytic technique and the study timeframe. This led to successful research outcomes that arguably would not have been achieved through alternative data collection methods. As such, future studies of paraphilic behaviour should seriously consider the benefits of asynchronous interviews in helping achieve their research aims and outcomes.

\section{Discussion questions suitable for classroom use}

- What advantages do online asynchronous interviews have over other forms of interview (both online and offline)?

- What advantages do online asynchronous interviews have over other forms of online data collection?

- This case touched only briefly on ethical issues. What kinds of ethical issues do you think are involved in the use of online asynchronous interviews? How can they be addressed?

- The study sample was recruited by posting recruitment adverts on online paraphilia forums. What might be the advantages and disadvantages to sampling in this way?

- How might online asynchronous interviews be used to collect data on other types of human behaviour? What would be the advantages and disadvantages of using such methods on behaviours other than paraphilias? 


\section{List of further readings}

Earls, C. M. \& Lalumière, M. L. (2009). A Case Study of Preferential Bestiality. Archives of Sexual Behavior, 38(4), pp. 605-609. DOI: 10.1007/s10508-007-9285-x

Griffiths, M. D. (2012). The use of online methodologies in studying paraphilias - A review. Journal of Behavioral Addictions, 1(4), pp. 143-150. DOI: 10.1556/JBA.1.2012.4.1

Meho, L. I., (2005). E-Mail Interviewing in Qualitative Research: A Methodological Discussion. Journal of the American Society for Information Science and Technology, 57(10), pp. 1284-1295. DOI: $10.1002 /$ asi.20416

Terry, L. L. \& Vasey, P. L. (2011). Feederism in a Woman. Archives of Sexual Behavior, 40(3), pp. 639-645. DOI: 10.1007/s105108-009-9580-9

\section{References}

Aggrawal, A. (2009). Forensic and Medico-legal Aspects of Sexual Crimes and Unususal Sexual Practices. Boca Raton: CRC Press.

Ahlers, C. J., Schaefer, G. A., Mundt, I. A., Roll, S., Englert, H., Willich, S. N. and Beier, K. M. (2011). How Unusual are the Contents of Paraphilias? Paraphilia-Associated Sexual 
Arousal Patterns in a Community-Based Sample of Men. Journal of Sexual Medicine, 8(5), pp. 1362-1370. DOI: 10.1111/j.1743-6109.2009.01597.x

Granello, D. H. \& Wheaton, J. E. (2004). Online Data Collection: Strategies for Research. Journal of Counseling and Development, 82(4), pp. 387-393. DOI: 10.1002/j.15566678.2004.tb00325.x

Griffiths, M. D. (2012a). The use of online methodologies in studying paraphilias - A review. Journal of Behavioral Addictions, 1(4), pp. 143-150. DOI: 10.1556/JBA.1.2012.4.1

Griffiths, M. D. 2012b. A crying shame: A brief overview of dacryphilia. Retrieved 28/07/2013 from: http://drmarkgriffiths.wordpress.com/2012/07/27/a-crying-shame-a-briefoverview-of-dacryphilia/ (last accessed: 01/08/2013).

James, N., \& Busher, H. (2006). Credibility, authenticity and voice: dilemmas in online interviewing. Qualitative Research, 6(3), pp. 403-420. DOI: 10.1177/1468794106065010

Jowett, A., Peel, E. \& Shaw, R. (2011). Online interviewing in psychology: Reflections on the process. Qualitative Research in Psychology, 8, pp. 354-369. DOI:

$10.1080 / 14780887.2010 .500352$ 
Love, B. (2001). Encyclopedia of Unusual Sex Practices. London: Greenwich Editions.

Okami, P. (2002). Causes and consequences of a career in sex research. In M. W. Wiederman \& B. Whitley (Eds.), Handbook for conducting research on human sexuality (pp. 505-512). Lawrence Erlbaum Associates: Mahwah, NJ.

Ross, M. W., Månsson, S-A., Daneback, K., Cooper, A. \& Tikkanen, R. (2005). Biases in internet sexual health samples: Comparison of an internet sexuality survey and a national sexual health survey in Sweden. Social Science \& Medicine, 61(1), pp. 245-252. DOI:10.1016/j.socscimed.2005.01.019

Scorolli, C., Ghirlanda, S., Enquist, M., Zattoni, S. \& Jannini, E. A. (2007). Relative prevalence of different fetishes. International Journal of Impotence Research, 19(4), pp. 432437. DOI: $10.1038 /$ sj.ijir.3901547

Willis, P. (2011). Talking sexuality online - technical, methodological and ethical considerations of online research with ethnic minority youth. Qualitative Social Work, 11(2), pp. 141-155. DOI: $10.1177 / 1473325011400488$ 